\title{
O QUE SIGNIFICAM AS OCUPAÇÕES DE IMÓVEIS EM ÁREAS CENTRAIS?
}

\author{
Thiago Aparecido Trindade*
}

\begin{abstract}
Adotando como referência empírica o movimento de moradia do centro de São Paulo, o presente artigo tem como objetivo principal analisar o significado das ocupações de imóveis ociosos promovidas por atores desse movimento na área central da cidade. Demonstramos, com isso, o papel dos movimentos sociais como atores que se colocam na posição de desafiantes das ideias, dos discursos e valores hegemônicos na sociedade. Por meio da fala dos próprios ativistas engajados nessa mobilização, discute-se também como o direito de morar no centro tornou-se uma pauta política gradualmente construída pelos setores populares. A metodologia adotada, de caráter predominantemente qualitativo, consistiu em revisão teórica, coleta de dados em documentos e material jornalístico e entrevistas com militantes. Como conclusão, sugerimos que o principal significado das ocupações nas áreas centrais consiste no questionamento do modelo hegemônico de urbanização na sociedade brasileira, que, historicamente, afastou as camadas mais pobres em direção aos cinturões periféricos das cidades.
\end{abstract}

Palavras-chave: Movimento de moradia. Ocupações. Conflito. Direito à cidade. Urbanização.

\section{INTRODUÇÃO}

A cidade de São Paulo é a mais rica do Brasil e, ao mesmo tempo, uma das mais desiguais do mundo. Para uma boa parte de sua população, morar em São Paulo significa percorrer grandes distâncias no deslocamento entre casa, trabalho e casa, conviver com uma infraestrutura urbana muitas vezes precária e (ou) insuficiente e enfrentar o alto valor do solo urbano - o que impacta diretamente no valor dos imóveis e no custo do aluguel da moradia. Tais dificuldades resultam, especialmente, de um modelo de crescimento urbano pautado pelos interesses do mercado especulativo de terras, setor articulado em maior ou menor medida com outros atores econômicos.

Esse modelo urbano - que, evidentemente, não é exclusivo de São Paulo - foi responsável pela produção de uma cidade segregada, onde o centro e suas adjacências foram predominantemente habitados pelos ricos e

* Universidade de Brasília - UnB. Instituto de Ciência Política. Campus Universitário Darcy Ribeiro, Prédio IPOL/IREL. Asa Norte. Cep: 70904-970. Brasília - Distrito Federal - Brasil. th.trindade83@gmail.com pela classe média, enquanto as classes mais pobres viram-se forçadas a residir nas localidades mais periféricas, o que significava um afastamento das melhores localizações da cidade. No decorrer do tempo, São Paulo testemunhou intensas lutas populares protagonizadas pela classe trabalhadora. No que se tem de registro, as primeiras mobilizações por melhores condições de moradia datam já do início do século XX (Kowarick; Ant, 1994). Ao longo da década de 1980, no contexto de ampla mobilização social contra o regime militar no Brasil, as ocupações de terrenos nas periferias de São Paulo, puxadas por movimentos organizados, ganham significativa visibilidade política (Doimo, 1995; Gohn, 1991). No decorrer dos anos 1990, a arena dessa luta é ampliada, e os movimentos de moradia da capital paulista passam a atuar também nas áreas centrais. A partir de 1997, as ocupações de terrenos, mas, principalmente, de imóveis ociosos no centro da cidade passam a ser realizadas com frequência pelo movimento de moradia. As ocupações do centro da cidade, protagonizadas por duas organizações, em especial, a União dos Movimentos de Moradia (UMM) e a Frente de Luta por Moradia (FLM), 
representam uma nova etapa na história da luta pela moradia popular em São Paulo (Neuhold, 2009; Trindade, 2014).

As ocupações são ações coletivas de alto risco. Como a história demonstra, a possibilidade de um desfecho violento em função de confronto com as forças policiais não é remota. Mesmo diante desse cenário, apenas no centro da cidade de São Paulo foram realizadas 105 ocupações em imóveis ociosos entre os anos de 1997 e 2012, uma média de 6,5 ocupações por ano. Um número nada desprezível, considerando-se todo o risco envolvido e também as dificuldades logísticas e organizacionais envolvidas na realização desse tipo de ação. Há de se considerar ainda que as condições de habitação dos imóveis ocupados pelos movimentos são, em geral, extremamente precárias, visto que alguns desses edifícios encontram-se abandonados há cerca de 15 ou 20 anos, oferecendo grande risco à integridade física dos militantes.

Em suma, ocupar um imóvel é algo extremamente complexo e arriscado. As razões pelas quais as pessoas fazem isso serão discutidas (mesmo que brevemente) neste texto. $\mathrm{O}$ fato é que, mesmo com todas as dificuldades e riscos envolvidos, os movimentos atuantes no centro de São Paulo conseguiram manter uma impressionante regularidade em termos de mobilização coletiva ao longo desses anos. సิ Mas, afinal, o que as ocupações no centro da cidade, iniciadas em 1997, representam? Partindo dessa questão geral, este texto se propõe $\frac{\pi}{2}$ a responder a três questões específicas: Quais são as condições urbanas objetivas que conforเి mam a ação política dos movimentos de moos radia no centro da cidade? Como o centro se ¿ tornou uma pauta política, ou seja, como foi iे possível mobilizar pessoas comuns e em con-

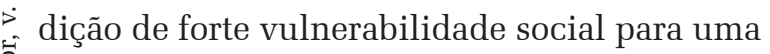
ação de alto risco? Por fim, o que as ocupações simbolizam em termos políticos e qual é o projeto de cidade subjacente a essa mobilização?

Com bases nessas questões, o objetivo central deste texto consiste em analisar o papel dos movimentos sociais como atores desa- fiantes. Os movimentos sociais lutam por mudanças nas políticas públicas, na legislação, na forma de distribuição da riqueza e nas regras institucionais de distribuição do poder (Della Porta; Diani, 2006; Gillion, 2013; Giugni, 1998). Nesse sentido, colocam-se na condição de desafiantes do sistema político, das elites e das autoridades (Tarrow, 2011; Tilly, 2010). E, como é lembrado por Tilly (2010, p. 137), “[...] as 'autoridades' podem também incluir donos de propriedades, funcionários religiosos, e outros cujas ações (ou omissões) afetam significativamente o bem-estar de muitas pessoas". Mas, ao mesmo tempo, a atuação dos movimentos sociais também se manifesta na esfera cultural, na medida em que eles confrontam os valores, discursos e códigos hegemônicos da sociedade, propondo novos projetos e olhares sobre determinadas questões (Melucci, 1989, 1996). O que analisamos aqui, portanto, é a atuação do movimento de moradia do centro de São Paulo no sentido de questionar e problematizar o modelo periférico de urbanização e, por meio das ocupações de imóveis ociosos nas áreas centrais, propor um novo modelo de organização da cidade.

As principais contribuições para a análise aqui realizada se localizam, por um lado, no debate teórico sobre segregação e periferização da pobreza (Caldeira, 2008; Villaça, 2001, 2011), e, por outro, no interior das teorias dos movimentos sociais, principalmente em autores e conceitos que contribuíram para iluminar o debate sobre a relação entre cultura e ação coletiva (Della Porta; Diani, 2006; Melucci, 1989, 1996; Snow, 2004; Snow et al., 1986). O texto se divide em três partes. Na primeira, apresentamos um panorama geral sobre segregação e periferização da pobreza, analisando os processos históricos, de cunho político e econômico, que contribuíram decisivamente para afastar as camadas populares do centro da cidade em direção às áreas periféricas. $\mathrm{Na}$ sequência, analisamos o momento em que os ativistas sociais engajados na luta pela moradia passam a olhar o centro da cidade como 
um território em disputa, construindo, a partir daí, um discurso capaz de mobilizar pessoas e, ao mesmo tempo, legitimar e justificar essa mobilização pela habitação popular nas áreas centrais. Para tanto, nos embasamos, principalmente, nas falas dos próprios protagonistas desse processo. ${ }^{1}$

Na terceira e última parte, trazemos o debate sobre a relevância política das ocupações de imóveis ociosos no centro da cidade. Entendemos que o principal significado dessas ações é que elas representam uma negação ao modelo periférico de urbanização. Simbolicamente, as ocupações no centro traduzem um esforço das camadas populares em reconquistar seu direito a usufruir do centro da cidade, conformando aquilo que alguns analistas acadêmicos e os próprios ativistas passaram a denominar como luta pelo direito à cidade, ou seja, a reivindicação da moradia em uma área da cidade bem servida por infraestrutura e equipamentos urbanos. Nesse sentido, defendemos que a ocupação representa uma forma de ação carregada de forte conteúdo simbólico, sintetizando ação, discurso e projeto de forma simultânea. Encerramos o texto com breves considerações sobre os elementos teóricos e empíricos apresentados ao longo da discussão.

\section{SEGREGAÇÃO, CONFLITO SOCIAL E PERIFERIZAÇÃO DA POBREZA}

O espaço urbano é produzido a partir dos conflitos entre diferentes classes e grupos sociais. Essa é uma premissa básica para qualquer análise dos processos urbanos. E, nesse sentido, um aspecto crucial para uma compreensão mais adequada do processo de produção da cidade é a importância da localização. Com efei-

${ }^{1}$ As entrevistas apresentadas neste artigo foram realizadas no segundo semestre de 2013, como parte de nossa pesquisa de doutorado desenvolvida junto ao programa de pós-graduação em Ciências Sociais do IFCH/Unicamp (sendo a tese defendida em maio de 2014). Apresentamos trechos das entrevistas realizadas com um dos coordenadores do Centro Gaspar Garcia de Direitos Humanos e um dos coordenadores da União dos Movimentos de Moradia (UMM-SP). to, determinadas localizações, na cidade, são muito mais bem equipadas e vantajosas do que outras, e, por isso, muito mais valorizadas. ${ }^{2}$ Flávio Villaça (2001) esboça uma tese que é central para o entendimento do nosso objeto de estudo: existe uma disputa entre as diferentes classes sociais pelas melhores localizações na cidade. Em outras palavras, existe uma luta política pela apropriação de uma riqueza socialmente produzida, nesse caso, a localização. Como é pontuado por Mike Davis (2006, p. 106), “[...] os conflitos de classe mais intensos por espaço urbano ocorrem no centro das cidades e nos principais entroncamentos urbanos".

As camadas populares almejam a moradia no centro e em suas adjacências em razão das inúmeras vantagens oferecidas por essa localização. Habitar e trabalhar no centro da cidade implica vantagens significativas para os mais pobres. Porém, justamente por ser uma área bem equipada e de infraestrutura consolidada, o centro oferece boas oportunidades de negócios e projetos imobiliários voltados para os estratos de renda mais elevada. Objetivamente, portanto, o centro da cidade se configura como palco de disputa política entre atores com projetos e interesses distintos.

Um conceito essencial para o entendimento dos conflitos sociais urbanos é o de segregação, que designa "[...] um processo segundo o qual diferentes classes ou camadas sociais tendem a se concentrar cada vez mais em diferentes regiões gerais ou conjunto de bairros da metrópole" (Villaça, 2001, p. 142, grifo nosso). O conceito de segregação refere-se, portanto, ao processo de afastamento de diferentes grupos e classes sociais na cidade - o que, vale lembrar, não significa isolamento. A segregação deve ser analisada sempre como processo, um fenômeno que se caracteriza pelo dinamismo e pelo movimento, não sendo, portanto, um quadro estático (Villaça, 2001).

${ }^{2}$ É claro que essa é uma questão relativa. Uma localização considerada boa para a realização de determinada atividade econômica ou social pode não ser tão vantajosa para outras atividades, mas não entraremos nesse nível de detalhamento. 
Isso significa dizer que nenhuma área da cidade será totalmente homogênea do ponto de vista de sua ocupação, isto é, nenhuma área segregada será exclusiva de alguma classe social, uma vez que a segregação sempre se refere a uma tendência de ocupação de uma localidade por determinados grupos, e não a algo cristalizado e homogêneo.

Apesar disso, a segregação deve ser interpretada como um processo dialético, o que significa que a presença de determinadas classes sociais em certas localidades inibe a presença de outras (Villaça, 2001). Na medida, por exemplo, em que o custo da terra urbana se torna muito alto em determinada localidade, isso favorece que essa área seja ocupada pelos mais ricos e cria dificuldades para que as classes de baixa renda lá permaneçam. Em linhas gerais, foi exatamente isso que aconteceu com as áreas centrais das cidades brasileiras ao longo do processo de urbanização. É evidente que as classes populares nunca estiveram totalmente ausentes do centro, ou seja, em nenhum momento histórico foi possível afirmar que o centro era ocupado totalmente pelas classes médias e altas. $\mathrm{O}$ que aconteceu, na verdade, foi que, em um determinado período da história, essa segregação se acentuou, dando origem ao modelo denominado centro-periferia ${ }^{3}$ (Caldeira, 2008; Kowarick, 1980, 2009; Marques, 2015; Moya, 2011).

No caso de São Paulo, Teresa Caldeira nos mostra que tal modelo se consolidou entre os anos de 1940 a 1980; o padrão centro-periferia, diferentemente do modelo anterior, é disperso ao invés de concentrado, uma vez que as classes sociais vivem afastadas umas das $\dot{2}$ outras, sendo "[...] as classes média e alta nos $\therefore$ bairros centrais, legalizados e bem-equipados; os pobres na periferia, precária e quase sempre $\doteq$ ilegal [...]" (Caldeira, 2008, p. 218). Na cidade capitalista, presa à lógica do valor de troca

${ }^{3} \mathrm{O}$ próprio modelo centro-periferia foi modificado posteriormente em função do deslocamento de setores de renda mais elevada em direção a regiões mais afastadas do centro, que passaram por um processo de valorização imobiliária. Isso não significa, entretanto, que o modelo centro-periferia foi anulado, mas sim que a organização espacial da cidade tornou-se mais complexa em decorrência da sobreposição de diferentes padrões de segregação.
(Harvey, 1980; Lefebvre, 2008), o mecanismo mais óbvio de exclusão social e de segregação opera através da dinâmica do mercado de terras. A especulação imobiliária - fenômeno crucial para a compreensão do processo de urbanização capitalista - consiste basicamente na retenção deliberada de terrenos e imóveis com base na expectativa de sua valorização futura. No Brasil, as cidades cresceram segundo a lógica dos interesses especulativos, isto é, o tecido urbano se ampliava horizontalmente não em função da necessidade de acomodar as pessoas no espaço, mas sim porque a retenção especulativa da terra impedia as classes mais pobres de se instalarem nas áreas mais valorizadas pelos agentes do mercado.

As localizações mais bem equipadas com serviços públicos e infraestrutura urbana foram historicamente reservadas para as classes mais abastadas, cujo poder de compra lhes permitia a inserção no mercado formal de terras (Maricato, 1996, 2000). A dinâmica especulativa do capital imobiliário, somada à não intervenção estatal nesse cenário, contribuiu para produzir uma situação na qual "[...] inúmeros terrenos vazios e/ou ociosos conformavam a paisagem urbana - um grande número deles, inclusive, na área central” (Trindade, 2012, p. 147-148). A Tabela 1 nos mostra o número de imóveis ocioTabela 1 - Domicílios vagos - Município de São Paulo e distritos da área central

\begin{tabular}{l|r|r}
\hline Município e distritos & $\mathbf{2 0 0 0}$ & $\mathbf{2 0 1 0}$ \\
\hline São Paulo & 420.327 & 293.621 \\
Bela Vista & 5.479 & 3.494 \\
Belém & 2.500 & 2.775 \\
Bom Retiro & 1.821 & 1.114 \\
Brás & 2.789 & 1.664 \\
Cambuci & 1.910 & 1.201 \\
Consolação & 3.694 & 2.890 \\
Liberdade & 5.283 & 3.166 \\
Mooca & 3.675 & 4.075 \\
Pari & 1.223 & 556 \\
República & 7.007 & 3.732 \\
Santa Cecília & 6.343 & 3.024 \\
Sé & 3.055 & 1.246 \\
\hline
\end{tabular}

Fonte: IBGE, Censos demográficos (2000, 2010). 
sos no Município de São Paulo e nos distritos que constituem o centro expandido, segundo os dados do Instituto Brasileiro de Geografia e Estatística para os anos de 2000 e 2010.

Como se percebe, a vacância imobiliária diminuiu significativamente entre os anos de 2000 e 2010 no município de São Paulo. Se, em 2000, havia 420.327 domicílios vagos, esse número caiu para 293.621 em 2010. Todos os distritos da área central acompanharam esse movimento de queda na vacância imobiliária, com exceção do distrito de Belém. Muito provavelmente, esses números se devem ao aquecimento da indústria da construção civil no período entre 2009 e 2013, principalmente, o que estimulou a produção de novos empreendimentos habitacionais e talvez tenha acelerado a ocupação de alguns que estavam vagos. Em relação aos distritos centrais, em 2000, havia um total de 44.779 imóveis vazios, o que corresponde a $10,6 \%$ do total do município. Em 2010, esse número caiu para 28.937 na área central, e correspondeu a 9,8\% do total. Ou seja, do ponto de vista percentual, uma ligeira oscilação para baixo, pouco significativa. O mais importante é compreender que, especialmente graças à especulação imobiliária, existe uma quantidade significativa de imóveis vagos no centro da cidade, cerca de $10 \%$ do total de imóveis vagos no município. E, além do mais, deve-se considerar o fato de que essa estimativa referente ao número de imóveis vagos está subestimada, pois existem inúmeros galpões e terrenos abandonados que não entram nesse cálculo (Bonfim, 2004).

Mas o fato é que o mercado não age sozinho na produção da cidade segregada. Historicamente, o Estado teve um papel crucial nesse processo, em especial por três razões principais: i) não regular a atuação dos agentes econômicos envolvidos na produção da cidade (Fernandes, 2007, 2010); ii) promover intervenções urbanísticas que encareceram o preço do solo nas áreas centrais (Bonduki, 1994); e iii) produzir habitação popular, via de regra, nas zonas periféricas, reforçando, dessa forma, a característica fundamental do padrão centro-periferia (Caldeira, 2008). Como nos recorda Mike Davis (2006), a intervenção do Estado no espaço urbano, desde a Paris de 1860 - objeto de remodelação urbanística proposta pelo Barão Haussmann - revela um padrão de atuação que objetiva conjugar o controle social e a maximização dos lucros dos agentes imobiliários. Ao expulsar os pobres e "higienizar" o centro, o Estado abre novas frentes de expansão para o capital, ao mesmo tempo em que canaliza a tensão social e as potenciais revoltas populares para a periferia, longe do aparato político-administrativo que governa o território urbano. A análise de Kowarick e Ant (1994, p. 79, grifo nosso) sobre o papel do Estado na produção da segregação urbana em São Paulo é ilustrativa:

O movimento operário na Primeira República (1889-1930) atinge seu ápice durante a greve geral de 1917. Neste particular, convém mencionar que a luta dos trabalhadores naquele ano não se deu em torno de sindicatos, centrando-se em torno das ligas de bairro. [...] assim, estas zonas populares que circundam as fábricas, onde predominam moradias da classe pobre, passam a ser encaradas como focos de desordem, 'epidemias anarquistas', semelhantes às moléstias contagiosas, que devem ser extirpadas do cenário da cidade. Sem lhe dar um valor primordial no intento de periferizar os trabalhadores não se pode desprezar este fator político enquanto causa da desconcentração da moradia operária ocorrida mais tarde, que, de alguns poucos locais sediados em torno de antigos centros fabris, irradia-se para inúmeras áreas da capital.

O centro é área de tensão social, palco das principais lutas e embates pela apropriação do espaço urbano. Seja de forma politicamente organizada ou não, as revoltas populares nas zonas centrais das grandes cidades sempre amedrontaram as elites. O esforço em periferizar a pobreza estava diretamente relacionado à necessidade de preservar a ordem política e social e estabelecer mecanismos de controle sobre os setores populares, dispersando-os pelo território e dificultando sua circulação pelo centro (Patto, 1999). A cidade torna-se uma máquina de produção de desigualdade. Não bastassem 
seus baixos níveis de rendimento econômico, as classes populares urbanas no Brasil teriam suas condições de vida consideravelmente pioradas em função do modelo de desenvolvimento urbano, conformando aquilo que Kowarick (1980) nomeou como espoliação urbana. Afundada em contradições, a cidade, que afastou os pobres para longe, tornar-se-ia palco de novos conflitos pela apropriação de seu centro.

\section{ENQUADRAMENTO INTERPRETA- TIVO E FORMULAÇÃO DISCURSI- VA DA LUTA PELA MORADIA NO CENTRO}

É amplamente aceito pelas teorias dos movimentos sociais que a mobilização coletiva não depende apenas de recursos organizacionais e de condições favoráveis no ambiente político. Do mesmo modo, a mobilização social não deriva automaticamente de questões estruturais, ou seja, não é porque existe pobreza e desigualdade que as pessoas afetadas por isso necessariamente se engajarão na mudança do status quo. Na realidade, nenhuma situação em si mesma gera algum tipo de mobilização; para que isso ocorra, é preciso que as pessoas percebam determinada situação como injusta, como uma "questão" que precisa ser resolvida. em mobilização (Alonso; Costa; Maciel, 2007).

Na verdade, não se trata apenas de interpretar uma determinada situação como injusta

Essa é, precisamente, a principal conribuição da perspectiva teórica dos frames da ação coletiva (Gamson, 1992; Snow, 2004; Snow; Benford, 1988; Snow et al., 1986). Os frames desempenham uma função interpretativa da realidade social, constituindo-se em instrumentos cognitivos que permitem aos ativistas questionar uma situação social até então não problemática, transformando descontentamento constatar que ela precisa ser modificada, mas também apontar para uma alternativa política concreta, que dê sentido à mobilização e ao engajamento coletivo. Benford e Snow (2000) se utilizam do verbo framing para conceituar esse trabalho interpretativo, que, por sua vez constitui-se de três etapas: a primeira delas é a diagnóstica (diagnostic framing), e consiste na identificação de uma situação injusta e na atribuição de responsabilidade a algo ou a alguém; a segunda etapa envolve o prognóstico da situação (prognostic framing) e passa pela definição de um plano e das estratégias de ação a serem empregadas na resolução do referido problema (Benford; Snow, 2000); a última etapa, denominada motivacional (motivational framing), pode ser entendida como um "chamado às armas". É a dimensão motivacional do frame, que conduz as pessoas à ação direta, produzindo a motivação e os incentivos necessários para a ação (Gamson, 1992; Della Porta; Diani, 2006).

É, enfim, através da construção de frames da ação coletiva que os movimentos sociais atribuem significados a eventos e situações relevantes na intenção de mobilizar seus potenciais aderentes e constituintes, ganhar o apoio da opinião pública e desmobilizar seus antagonistas (Benford; Snow, 2000; Snow; Benford, 1988). Ou seja, o frame é voltado tanto para dentro quanto para fora do movimento social. Não se trata somente de mobilizar pessoas, mas construir um discurso que justifique e legitime essa mobilização frente à opinião pública e às autoridades políticas (D’Anjou; Male, 1998; Tarrow, 2011).

Ocorreu do mesmo modo com a pauta da luta pela moradia popular nas áreas centrais da cidade. A mobilização coletiva em prol do direito de morar no centro não foi um desdobramento natural dos problemas estruturais advindos da urbanização periférica, mas sim do esforço de um conjunto de indivíduos que passaram a enxergar a luta no centro como uma possibilidade e, mais do que isso, uma necessidade. Essas afirmações não ignoram a importância dos fatores estruturais para a mobilização coletiva. Com efeito, é claro que as precárias condições de vida dos moradores da periferia e as grandes distâncias a serem percorridas no dia a dia, dentre outras questões, 
constituem-se em elementos objetivos, que são pontos de partida importantes para a mobilização política, mas não suficientes para que ela se concretize (Ribeiro, 1989).

O centro da cidade foi descoberto pelos movimentos de moradia em São Paulo - e no Brasil, de um modo geral - de forma relativamente tardia. Inicialmente, a atuação desses movimentos populares era focada nas áreas periféricas do tecido urbano. O formato atual do que hoje se conhece como "movimento de moradia” em São Paulo começa a adquirir contornos mais específicos ao longo da década de 1980, quando as lutas populares contra o regime militar no Brasil alcançaram um alto grau de adesão popular. A luta que surge inicialmente na periferia da cidade, em prol de melhores condições de vida e pela regularização de loteamentos clandestinos em benefício da população favelada, contribuirá para o nascimento de diversas organizações populares responsáveis por canalizar as demandas dessa população ao poder público (Blikstad, 2012; Gohn, 1991; Tatagiba; Paterniani; Trindade, 2012).

Uma vez que o grosso da população mais pobre residia nas zonas mais longínquas do centro (no caso de São Paulo, sobretudo nas zonas leste e sul), é compreensível que as primeiras organizações populares voltadas para a luta pela moradia tenham surgido nos cinturões periféricos da cidade. Em um contexto de forte crise econômica, aumento no valor do solo urbano, no preço dos alugueis e nos índices de desemprego, as ocupações de terras nas periferias vão se intensificar significativamente.

O contexto de crise econômica, todavia, não afetava apenas os trabalhadores de baixa renda da periferia. Os moradores de cortiços nas áreas centrais também sofriam com a inflação e com as taxas abusivas cobradas pelos administradores. Para uma breve definição, cortiço, nas palavras de Pasternak (1997, p. 75 apud Kowarick, 2009, p. 112), “[...] significa literalmente ninho de abelhas". O cortiço é formado numa casa de cômodos de aluguel, na qual as pessoas compartilham diversos espaços (como banheiros e tanques) e vivem em condições extremamente degradantes, "[...] exercendo diferentes funções em um mesmo ambiente" (Neuhold, 2009, p. 30). Por um longo tempo, a população encortiçada foi vista por muitos militantes sociais como um grupo inviável de ser mobilizado, incapaz de incorporar a disciplina necessária que o ativismo político requer. Através de uma entrevista com um dos coordenadores do Centro Gaspar Garcia de Direitos Humanos 4 , Miagusko (2008, p. 130131, grifo nosso) nos mostra que, inicialmente, havia uma resistência das próprias lideranças dos movimentos de moradia em atuar de forma mais incisiva no centro da cidade:

A gente discutia muito a questão do Centro, mas
muito focada na questão da população de rua, ca-
tadores, crianças de rua. E um dos problemas que
aparecia além da população de rua, criança, era a
questão da moradia em cortiço. [...] a gente começou
a ter muitos despejos. E era uma época também de
inflação, a questão de valor de aluguel que aumen-
tava de forma irregular, a questão da água e da luz.
E aí começamos a discutir o Centro um pouco mais
focado na questão da habitação. Tanto que a partir
da articulação desses grupos, a partir de [19]84, a
gente começa a formar o Centro de Defesa Direitos
Humanos. Em [19]88, esse centro passa a chamar
Centro Gaspar Garcia de Direitos Humanos. E aí
com uma bandeira, que era morar dignamente no
Centro. Agora a mobilização do Centro, parecia que
ele não era ator. O centro sempre teve muita dificul-
dade. E depois também se tinha um certo mito de
que na população de cortiço não é possível mobili-
zar. Eu lembro de ter discutido com lideranças: no
cortiço não dá, não tem espaço, as pessoas não fa-
lam, ninguém quer saber muita coisa. Então parece
que tinha uma certa acomodação dos educadores,
que não fosse possível mobilizar. Todos que atua-
vam nas lutas da periferia não acreditavam muito.

${ }^{4}$ O Centro Gaspar Garcia de Direitos Humanos é um dos principais parceiros e apoiadores do movimento de moradia do centro de São Paulo. O Gaspar Garcia também desenvolve trabalhos em parceria com o Instituto Pólis e com o Núcleo de Habitação e Urbanismo da Defensoria Pública de São Paulo (outros dois importantes parceiros do movimento de moradia), como publicações, seminários, ciclos de debates, oficinas e jornadas sobre o projeto de habitação popular no centro da cidade. Para maiores detalhes sobre o papel do Centro Gaspar Garcia na construção da luta pela moradia na área central de São Paulo, ver a tese de Miagusko (2008, p. 129-134).

${ }^{5}$ Entrevista, coordenador do Centro Gaspar Garcia de Direitos Humanos. In: Miagusko, 2008, p. 130-131, grifo nosso. 
Os trabalhadores residentes nos cortiços da área central aparecem nas falas de muitos ativistas da época como uma população deslocada, irrepresentável, inviável de ser mobilizada (Miagusko, 2008). Graças ao trabalho de um conjunto de educadores sociais (que também desempenhavam papel de articulação política entre as lideranças dos movimentos populares), ligados especialmente ao Centro Gaspar Garcia de Direitos Humanos, à Associação dos Trabalhadores de Quintais e Cortiços da Mooca e da Pastoral da Moradia, a luta pela moradia no centro começará a florescer justamente através desse canal: os moradores de cortiços. São esses moradores que irão contribuir decisivamente para fazer do centro "um ator" no cenário político da cidade de São Paulo.

Nesse momento inicial (segunda metade da década de 1980), no qual se assiste à emergência da luta popular no centro, ainda não se pode visualizar um movimento de moradia ou de sem-teto. É uma luta em defesa dos direitos dos moradores de cortiços explorados pelas altas taxas de água, luz e IPTU (Benoit, 2000), além de denunciar as péssimas condições de vida no local de moradia e os abusos de poder dos proprietários dos cortiços e dos intermediários. Esses últimos, com o aval dos proprietários, costumeiramente expulsavam ^ do cortiço as pessoas que não dispunham de : fôlego financeiro suficiente para arcar com as despesas do mês, que aumentavam indis: criminadamente, num contexto de inflação populares habitarem as áreas centrais da cidade. Se, antes, o desafio foi o de mobilizar a população dos cortiços, agora (já na década de 1990) os esforços se concentraram na construção de argumentos capazes de justificar e articular a luta pela moradia popular no centro de São Paulo. O tema dos cortiços, com as organizações criadas para representar a população encortiçada, não desaparece. O que acontece é uma ampliação da discussão política e da própria arena de atuação do movimento de moradia da cidade, até então mais direcionada às áreas periféricas. Essa ampliação da luta política no centro de São Paulo acontece com base em uma crítica ao modelo de urbanização periférico. A fala do coordenador do Centro Gaspar Garcia ressalta, novamente, a importância das organizações apoiadoras dos movimentos populares na construção da mobilização pelo direito à moradia no centro:

[...] tinham sido feitos levantamentos pelos próprios movimentos em anos anteriores sobre a quantidade de prédios vazios que existia no centro. E tinha também toda a discussão da política habitacional do Banco Nacional de Habitação (BNH) que provocou a periferização da pobreza. Outra questão era o caos urbano que se tinha na cidade de São Paulo, que desde a década de 1980 já tinha muitos congestionamentos. Quando os movimentos iniciam os levantamentos, começa a se perceber a grande quantidade de prédios vazios. E aí começam a se discutir esses dados sobre imóveis vazios e questionar as péssimas condições de vida nos cortiços. E então começa se perceber o seguinte: lugar pra morar tem, se a gente não mora é porque tem gente deixando imóvel vazio pra especulação. E essa constatação estimulou as ocupações. E nesse processo de organização dessa luta, além do Gaspar Garcia, a Associação dos TrabaIhadores da Mooca e a Pastoral da Moradia, além de várias lideranças que foram surgindo nesse processo de construção desse movimento, tiveram um papel importante (Entrevista, coordenador do Centro Gaspar Garcia de Direitos Humanos, 2013, grifo nosso).

De um lado, o modelo periférico de urbanização criou as condições objetivas para a emergência da luta pela moradia no centro. Do outro, lideranças e educadores sociais ligados ao movimento de moradia de São Paulo criaram 
as condições subjetivas do conflito, contribuindo para o trabalho de enquadramento interpretativo responsável pela mobilização. Os inúmeros prédios, galpões e terrenos abandonados em favor da especulação imobiliária no centro da cidade tornam-se objeto de contestação pública na fala dos ativistas. A fala de outra liderança importante do movimento de moradia do centro (a Frente de Luta por Moradia) ilustra com maiores detalhes a construção do argumento:

Então, essa luta dos sem-teto, quando se fala morar no Centro, compactar, ela é uma luta para transformar a cidade em uma cidade viável. São Paulo é inviável. Como é que faz? Não sei se você conhece a periferia, mas se você tiver oportunidade, o próprio movimento, nós temos trabalhos em várias pontas da cidade. Você vai andar lá e fala: 'pô, mas aqui não tem nada'. Não tem emprego, não tem nada. Tem asfalto, tem aquelas coisinhas, mas não é cidade, o cara dorme ali. Aquilo não é cidade. Então, se você comparar com Barcelona, o centro de São Paulo daria pra morar, aqui a região da Sé, daria pra morar mais 300 mil moradores, mais ou menos. É rarefeita a densidade, populacional aqui no Centro. Tem cerca de 160 habitantes por $\mathrm{km}^{2}$, quando um padrão razoável é de 400 a 450 habitantes/ $\mathrm{km}^{2}$. Então, você teria uma cidade em $750 \mathrm{~km}^{2}$, agora você tem uma cidade em $1.500 \mathrm{~km}^{2}$. Então, significa o quê? Transporte, deslocamentos, significa destruir matas ao seu redor, destruir fontes, destruir rios, significa espalhar lixo. Mas significa também que uma pessoa tem que se deslocar duas horas por dia pra ir até o seu trabalho. É uma série de impactos negativos. Então, a luta dos sem-teto, quando se fala 'quero morar no Centro', nós falamos que tem que mesclar a população: você tem que ter classe alta, classe média e classe baixa. Então, a luta dos sem-teto, na verdade é uma luta pelo direito à cidade ${ }^{6}$ (Aquino, 2008, p. 59-60, grifo nosso).

Desse modo, a luta pela habitação no centro coloca uma questão que vai além da moradia em si. O direito à cidade não é equivalente ao direito à moradia; o primeiro é muito mais amplo e complexo, pois considera a localização do indivíduo no sistema urbano em seu conjunto e a possibilidade de acesso às melhores localizações da cidade (Fernandes, 2007; Tavolari,
2016; Trindade, 2012). Vale observar que, no vocabulário mobilizado pelos próprios atores sociais engajados nessa mobilização, o termo "direito à cidade" tornou-se praticamente um sinônimo da luta pela moradia nas áreas centrais, visto que elas são, grosso modo, as áreas mais bem servidas por equipamentos urbanos, infraestrutura e ofertas de empregos atraentes.

Para as classes populares, aliás, a importância do centro vai muito além de suas vantagens materiais. Do ponto de vista simbólico, em certo sentido, as camadas populares entendem o centro como sinônimo da própria cidade. Tomando São Paulo como referência empírica, Kowarick (2009) faz alguns apontamentos nessa direção, ao estabelecer um parâmetro comparativo sobre as vantagens de se habitar o centro ou a periferia de uma grande cidade, a partir de entrevistas realizadas com os próprios habitantes desses locais. O centro, a despeito de alguns problemas como os altos preços dos aluguéis e as precárias condições de vida nos cortiços, é o lugar "onde tudo acontece", o principal lócus do convívio e do encontro social, onde há alternativas de lazer e diversão disponíveis mesmo para os mais pobres. Por isso, essa simbologia que envolve o centro das grandes cidades também contribui, de certa forma, para a associação entre a cidade e o centro.

Não é por acaso que as classes populares nunca quiseram abandonar o centro. Em muitos casos, aqueles que migraram para a periferia não o fizeram por vontade própria, mas por fatores estruturais que os coagiram a agir dessa forma. A rigor, os mais pobres sempre tentaram estabelecer residência o mais próximo possível das áreas centrais. Essa relação histórica dos trabalhadores com o centro, portanto, certamente foi um elemento importante para a construção do enquadramento interpretativo da luta pelo direito à cidade. Como será demonstrado a seguir, as ocupações de imóveis ociosos tornaram-se o símbolo maior dessa luta no decorrer dos anos. 


\section{AS OCUPAÇÕES NO CENTRO: desafio ao modelo hegemônico de cidade}

Como já foi apontado anteriormente, o ano de 1997 constitui um marco na luta pela moradia popular em São Paulo. É a partir dessa data que as ocupações em imóveis ociosos nas áreas centrais tornam-se uma prática sistemática do movimento de moradia da capital. O Gráfico 1 nos mostra a quantidade de ocupações realizadas no território denominado centro expandido de São Paulo ${ }^{7}$, no período entre 1997 e $2012 .{ }^{8}$

\section{Gráfico - Número de ocupações em imóveis ociosos no centro}

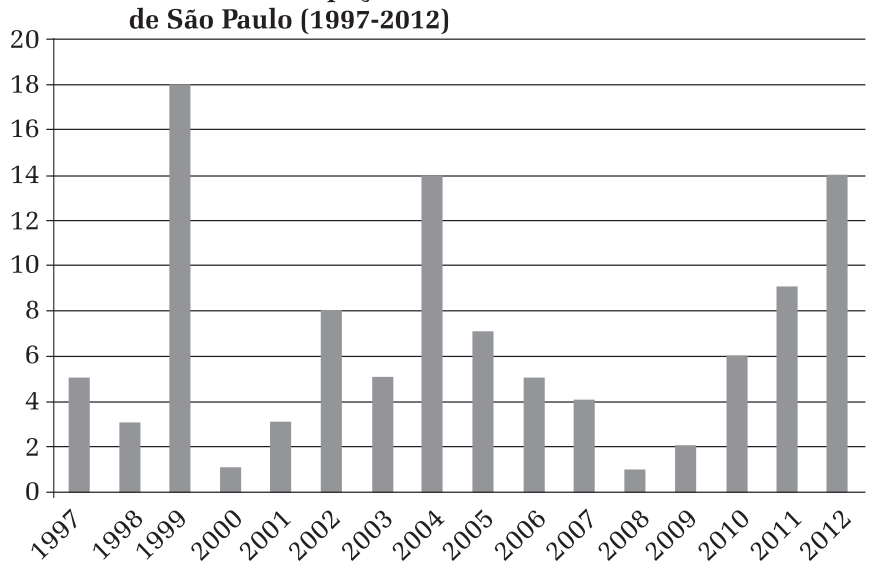

Fonte: Para os anos de 1997 a 2007, Neuhold (2009); para 2008 a 2012, levantamento realizado na versão on-line do jornal Folha de São Paulo e nos sites das organizações estudadas.

Como se nota, no período mais recente (2010-2012), o número de ocupações vem aumentando gradualmente, após um momento \& pações, mas que não nos parece ter sido muito के significativa: na realidade, o que houve foram $>$

ธิ 7 O centro expandido de São Paulo é constituído pelos distritos que integram a subprefeitura da Sé e a subprefeitura da Mooca. A primeira é composta pelos distritos da Sé, República, Bela Vista, Bom Retiro, Santa Cecília, Cambuci, Iiberdade e Consolação, enquanto a segunda é formada pelos seguintes: Belém, Brás, Mooca e Pari.

${ }^{8}$ Até o ano de 2007, os dados são extraídos do trabalho de Neuhold (2009). Para obter os dados entre 2008 e 2012, realizamos pesquisa em material jornalístico e nos sítios eletrônicos dos movimentos que atuam no centro. picos nos anos de 1999, 2004 e 2012, sendo que os anos de 2002 e 2011 também apresentaram números relevantes. Os picos verificados nesses três anos podem ser explicados pela ocorrência de megaocupações, ou seja, de ocupações simultâneas em vários imóveis no centro. ${ }^{9}$ Segundo Neuhold (2009), a primeira megaocupação promovida pela UMM ocorreu em outubro de 1999, reunindo um total de 6.100 pessoas que ocuparam seis imóveis na cidade de São Paulo, quatro deles no centro. A referida autora identificou, entre 1997 e 2007, um total de nove megaocupações: seis promovidas pela UMM (outubro de 1999, maio de 2002, abril de 2004, março e novembro de 2005 e abril de 2007), três pela FLM (outubro de 2004, novembro de 2005 e outubro e 2006), e uma pelo MSTC em julho de 2003 (Neuhold, 2009).

Além dessas ocupações, nossa pesquisa documental e em material jornalístico identificou mais três ações desse tipo. Em outubro de 2010, quatro edifícios foram ocupados pela FLM; em novembro de 2011, a UMM, a FLM e o MMRC ocuparam, de forma articulada, nove imóveis abandonados (onde se estima que foram mobilizadas 3,5 mil pessoas); e, por fim, em outubro de 2012, a FLM ocupou nove imóveis na área central. Entre 1997 e 2012 ocorreram, portanto, 12 megaocupações na área central da cidade. É interessante perceber como, apesar da relativa oscilação numérica em termos da quantidade de ocupações realizadas anualmente, o movimento de moradia manteve uma vitalidade inquestionável em termos de mobilização coletiva ao longo desses anos. ${ }^{10}$

Nossa pesquisa empírica detectou, porém, que, mesmo antes de 1997, já eram realizadas ocupações no centro da metrópole

9 Para mais informações sobre as megaocupações, ver Neuhold (2009).

${ }^{10}$ Para uma análise mais detalhada dos dados apresentados, ver Trindade (2014). 
paulista. Essa informação apareceu em depoimentos de alguns entrevistados, e também em conversas informais com pessoas ligadas aos movimentos de moradia. Ora, o que há, então, de singular nas ocupações pós-1997? O que acontece nessa data que a torna tão relevante na memória dos atores ligados à luta pela moradia no centro de São Paulo?

As ocupações nas áreas centrais anteriores a essa data, ao que tudo indica, não estavam sob a coordenação de grupos políticos específicos organizados na forma de movimentos sociais. Eram ações de caráter "espontâneo" (com todas as ressalvas que o termo traz consigo), conduzidas por famílias que haviam sido despejadas de cortiços ou de outras áreas ocupadas no centro da cidade. De acordo com Neuhold (2009, p. 51), a grande novidade nas ocupações iniciadas a partir de 1997 era o seu caráter amplamente coordenado e articulado, construído a partir de uma pauta pré-estabelecida de reivindicações "[...] e com uma rede de apoiadores que produziram ou consolidaram 'discursos' sobre o direito da população de baixa renda habitar uma área consolidada da cidade". Os depoimentos dos entrevistados corroboram esta tese:

[...] sempre teve grupos que ocuparam prédios abandonados [no centro]. Às vezes famílias despejadas de cortiços, que foram sem ter uma organização política por trás, sem ter uma dimensão política do problema. Mas 1997 se diferencia porque as ocupações passam a ter uma dimensão política. Passa a ter uma coordenação, data, hora combinada, chegada em massa, então passa a ter também uma expressão política, e não apenas por necessidade (Entrevista, Coordenador do Centro Gaspar Garcia de Direitos Humanos, 2013).

A particularidade depois de 1997 é que há uma tomada de consciência dos movimentos de moradia do centro, não só do centro, mas do conjunto dos movimentos de moradia da cidade de São Paulo, sobre a importância da gente ter uma política mais sistematizada para a área central de São Paulo. Os movimentos passaram a perceber que o centro era um território em disputa. Em 1997, você tem duas grandes ocupações no centro da cidade de São Paulo, uma na Rua do Carmo e outra na Nove de Julho. E nós con- sideramos estas duas ocupações como um marco na luta organizativa dos movimentos, e marca a entrada dos movimentos de vez na disputa pelo território do centro de São Paulo. A questão é que depois de 1997, as ocupações no centro se tornam uma ação sistemática (Entrevista, coordenador da UMM, 2013).

Como se percebe na fala dos entrevistados, 1997 torna-se um marco importante na medida em que representa o início de uma luta conduzida de forma articulada e estruturada por um conjunto de atores, com base em uma pauta política específica, apresentada ao poder público e à sociedade a partir de um conjunto de reivindicações. As ocupações no centro, outrora promovidas de forma espontânea e intermitente, tornam-se uma ação sistemática dos movimentos de moradia da cidade de São Paulo. Isso significa que os atores sociais responsáveis pela construção dessa mobilização foram capazes de deslocar o problema de famílias sem-teto da esfera privada para a esfera pública, uma vez que a entrada dos movimentos sociais no cenário em questão tornou público e atribuiu uma qualidade de conflito político a um problema que, até então, não era tratado dessa forma.

Percebemos isso como um fenômeno de grande relevância analítica. As ocupações de imóveis no centro de São Paulo, como ações politicamente organizadas e articuladas, marcam, indubitavelmente, um ponto de inflexão na luta pela moradia popular na cidade.

Nesse sentido, entendemos que o principal significado dessas ações, segundo nossa interpretação, é que elas representam uma negação ao modelo de urbanização historicamente consolidado na sociedade brasileira, responsável por afastar as camadas populares das áreas mais valorizadas da cidade. Simbolicamente, as ocupações no centro da cidade representam uma tentativa de as classes populares "reconquistarem” (pela via da luta política) determinadas áreas do território urbano que, ao longo da história, lhes foram "tomadas" pelos setores hegemônicos. A disputa entre as classes sociais pelas melhores localizações na cidade sempre 
existiu e assumiu variadas formas ao longo do tempo. Mas, em certo sentido, as ocupações representam uma politização até então inédita da questão, simbolizando o momento no qual os movimentos de moradia de São Paulo passam a contestar um dos mais importantes privilégios das classes mais abastadas. Em suma, as ocupações podem ser interpretadas como um "manifesto" subscrito por um conjunto de cidadãos que se negavam a permanecer nos lugares socialmente estabelecidos para eles. ${ }^{11}$

As ocupações, nesse sentido, não expressam "apenas" uma luta por um direito, mas outra concepção de cidade, que relega a lógica do mercado a um segundo plano. Utopia? Sem dúvida. Mas uma utopia já parcialmente realizada no presente. Ao ocupar esses imóveis, os militantes do movimento se tornam moradores do centro da cidade, afirmam para a sociedade que ali é o lugar deles. Nas palavras de Alberto Melucci (1989, p. 62): “[...] os movimentos [...] praticam no presente a mudança pela qual eles estão lutando [...]", configurando aquilo que pode ser denominado como política prefigurativa (Paterniani, 2013). É fundamental, nesta análise, realçar o caráter simbólico das ocupações no centro, seu sentido particular como forma de ação coletiva. Melucci (1989, p. 62) nos recorda que a forma organizacional dos movimentos sociais pode ser interpretada

¿ ${ }^{11}$ É necessário lembrar que esta é uma interpretação den๙ tre várias outras possíveis. O analista pode, a depender da sua perspectiva e abordagem teórica, chegar a diferentes conclusôes sobre o significado das diversas formas de ação

${ }^{12}$ Uma interessante análise sobre as formas de organização dos movimentos sociais também pode ser encontrada em Glemens (2010). centro da cidade, mas sim à ocupação como estratégia de mobilização dos movimentos sociais de luta pela terra, seja nas áreas rurais ou nas áreas urbanas, no centro ou na periferia dessas últimas. A simbologia das ocupações de terras e imóveis ociosos está diretamente relacionada ao conflito que elas expõem: o problema da concentração fundiária, ou seja, do acesso das camadas populares à terra ou à moradia. Ao ocupar terras e imóveis ociosos, os movimentos sociais estão questionando o direito irrestrito de propriedade dos setores economicamente dominantes da sociedade. Em tempo: a rigor, essa luta não contesta o direito de propriedade stricto sensu, isto é, não coloca em xeque o estatuto jurídico da propriedade privada, mas, antes, problematiza o fato de a estrutura fundiária ser altamente concentrada. É uma reivindicação que, caso plenamente concretizada, criaria milhões de novos proprietários. Ou seja, ao menos no plano imediato, trata-se de uma luta pela democratização da propriedade privada, e não pela sua extinção (Trindade, 2015a).

Há muitas similaridades entre a luta dos sem-teto e dos sem-terra. Sinteticamente, pode-se afirmar que esses movimentos lutam pela função social da propriedade, o que significa lutar contra o uso especulativo da terra. O principal argumento utilizado pelos movimentos em favor das ocupações está relacionado justamente a esse ponto: é injusto que milhões de pessoas não tenham terra para plantar ou casa para morar, enquanto os grandes proprietários mantêm seus imóveis vazios à espera de valorização (Trindade, 2015a). Cabe lembrar que o princípio da função social da propriedade está previsto na principal lei brasileira, a Constituição Federal de 1988, em seus Artigos 5, 170, 182 e 184, o que confere inegável respaldo jurídico tanto às reivindicações desses movimentos como às ocupações como forma de mobilização coletiva (Boulos, 2012; Fernandes, 2008; Melo, 2013; Trindade, 2015a).

Contudo, a despeito da legitimidade jurídica dessas ações, contestar os privilégios das classes dominantes nunca é tarefa simples do 
ponto de vista político no âmbito de uma sociedade capitalista, em especial quando se trata do direito de propriedade. No caso do Brasil, talvez esse quadro seja mais complexo em função de nossa herança colonial e da mentalidade patrimonialista fortemente arraigada no tecido social (Maricato, 2000; Schwarz, 2000), o que faz com que a propriedade privada seja um princípio defendido inclusive por aqueles que não a detêm (Tatagiba; Paterniani; Trindade, 2012, p. 413). ${ }^{13}$ As ocupações, portanto, carregam forte conteúdo simbólico de caráter contestatório, o que enceta profundas controvérsias na opinião pública e aciona conflitos fortemente relacionados à nossa histórica desigualdade social, expondo diversas lacunas e contradições da democracia brasileira (Fernandes, 2008; Trindade, 2015b).

Curiosamente, o debate teórico sobre repertório de confronto parece ter dedicado relativamente pouca atenção a essa dimensão de análise. A versão inicial do conceito de repertório designava, basicamente, um conjunto de formas de ação, numa referência aos diferentes modos através dos quais as pessoas se manifestam coletivamente. Em sua origem, o conceito proposto por Charles Tilly (1978) possuía um viés predominantemente estrutural, muito mais voltado para a análise das formas do que dos conteúdos da ação coletiva (Alonso, 2012). Em outras palavras, o conceito de repertório não nos possibilitava enxergar a fundo os significados embutidos nas formas de ação empregadas pelos diferentes atores. Em texto importante, McAdam, Tarrow e Tilly (2009, p. 25) reconheceram e apontaram para esse problema, alegando que o termo repertório possui uma "lógica expressiva" - no sentido de expressão de concepções, valores e ideologias - que raramente foi reconhecida pelos estudiosos. ${ }^{14}$

\footnotetext{
${ }^{13}$ Para uma análise mais profunda sobre essa questão, ver Trindade (2015a).

${ }^{14}$ Após sofrer críticas e problematizações, o conceito foi reformulado para equacionar esse problema e incorporar, com maior ênfase, a questão dos conteúdos simbólicos das formas de ação (Alonso, 2012). Em alguns dos últimos escritos de Tilly $(2006,2008)$ e na última versão do famoso livro de Tarrow, Power in Movement (2011), a noção de performance é adicionada ao conceito de repertório com a intenção de conferir maior destaque à capacidade de agên-
}

A dimensão simbólica (ou a "lógica expressiva” das ocupações) é algo muito evidente, e as ocupações no centro da cidade, nesse sentido, estão imbuídas de um duplo significado: além de questionar os privilégios dos grandes proprietários, essas ações também questionam o modelo de urbanização que se consolidou historicamente no país. Como sublinhado por Della Porta e Diani (2006, p. 107), os "[...] movimentos sociais desafiam as formas de dominação profundamente incorporadas nas práticas culturais, estilos de vida e hábitos mentais". No caso em questão, trata-se de uma contestação direta à ideia de que o lugar dos pobres é na periferia. Historicamente, o argumento mobilizado pelo discurso hegemônico para naturalizar a periferização da pobreza baseou-se no alto custo dos terrenos nas áreas centrais. A impossibilidade de se produzir habitação popular no centro da cidade derivava de uma constatação "técnica", e, portanto, "realista". A produção habitacional em massa para os mais pobres somente poderia ocorrer, por essa lógica, onde as terras eram mais baratas - leia-se, na periferia. Segundo a análise do coordenador do Centro Gaspar Garcia, as ocupações no centro tiveram papel relevante para problematizar essa concepção:

Antes dos movimentos no centro, qualquer gestor
público era categórico: é impossível fazer habitação
popular nas áreas centrais, o preço da terra é muito
caro, é inviável. Depois, nesse processo de discus-
são e de ocupações, teve vários estudos também que
colaboraram com a crítica à periferização da pobre-
za, cada vez mais se consolidou a ideia da moradia
de interesse social no centro. Isso tem sido consoli-
dado, de certa forma, graças às ocupações, que en-
volveu muita gente a estudar o assunto. E esses es-
tudos mostram que o custo da terra até é mais caro,
mas, se você pensar em termos do custo total para
a cidade, não é tão caro assim. Hoje existem mui-
tas justificativas favoráveis, até pela dificuldade de
mobilidade na cidade (Entrevista, coordenador do
Centro Gaspar Garcia de Direitos Humanos, 2013).
Por isso, o conflito instituído pelo mo-
ento de moradia através das ocupações de
os atores e à dimensão simbólica da ação.
cia dos atores e à dimensão simbólica da ação. 
imóveis ociosos nas áreas centrais vai de encontro ao argumento dos "especialistas". As ocupações representam, ao mesmo tempo, uma reivindicação e uma denúncia: a moradia no centro torna-se um direito reivindicado na medida em que se constata (e se denuncia) que o deslocamento dos mais pobres em direção às áreas periféricas é fruto de um processo histórico de concentração da riqueza e da propriedade, e não o desdobramento inevitável da realidade. A clássica formulação de Alberto Melucci (1989, p. 62) nos cai como uma luva: “[...] porque o desafio afeta os códigos culturais, a mera existência de um movimento é uma reversão dos sistemas simbólicos dominantes [...]”. Ainda segundo o pensador italiano, a função dos movimentos sociais consiste em

[...] revelar os projetos, anunciar para a sociedade que existe um problema fundamental numa dada área. Eles têm uma crescente função simbólica [...]. Eles não lutam meramente por bens materiais ou para aumentar sua participação no sistema. Eles lutam por projetos simbólicos e culturais, por um significado e uma orientação diferentes da ação social. Eles tentam mudar a vida das pessoas, acreditam que a gente pode mudar nossa vida cotidiana quando lutamos por mudanças mais gerais na sociedade (Melucci, 1989, p. 59).

Não se trata, evidentemente, de subestimar a importância das conquistas materiais, es¿ pecialmente em se tratando de um movimento ç. cuja demanda mais óbvia é um bem material. Nesse quesito, aliás, é importante registrar que o movimento de moradia conquistou cerca de 尺ี 3.500 unidades habitacionais no centro de São Paulo entre o início da década de 1990 e o ano $\dot{2}$ de $2012 .{ }^{15} \mathrm{O}$ que precisa estar claro é que a luta

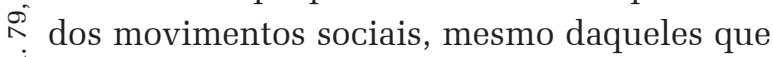
litam efetivamente por demandas materiais, $>$ não se restringe a essa dimensão. O caso do

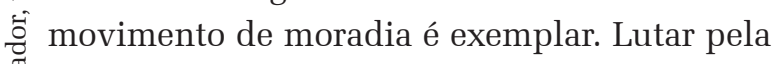

-15 No início da década de 1990, durante o governo municipal de Luiza Erundina (PT), os movimentos de moradia conseguiram estabelecer projetos em conjunto com a prefeitura e foram construídas cerca de 227 unidades para habitação popular no centro. Todas as demais unidades habitacionais conquistadas pelos movimentos foram construídas após o início das ocupações, em 1997. casa, e, ainda mais, lutar pela casa no centro da cidade, não significa apenas lutar pela casa. Ao ocupar um imóvel e demandar sua desapropriação, o movimento institui um conflito de ordem simbólica e ideológica de grandes proporções.

Afinal, para essas pessoas, lutar pelo direito de morar no centro significa, em grande medida, desafiar a lógica segundo a qual elas foram "educadas" durante toda sua vida: lugar de pobre é na periferia. Nessa perspectiva, faz todo o sentido a afirmação de Melucci de que a "mera" existência de um movimento social já representa um desafio ao sistema político. $\mathrm{Na}$ verdade, poderíamos ir além e afirmar que a organização política em torno dessa pauta e o "simples" questionamento das hierarquias sociais por meio dessa mobilização já representa, em grande medida, uma conquista popular.

\section{CONSIDERAÇÕES FINAIS}

Adotando o movimento de moradia do centro de São Paulo como referência empírica, este texto procurou analisar o papel dos movimentos sociais como atores que desafiam o discurso e os códigos hegemônicos. Mais especificamente, procuramos demonstrar que os ativistas engajados em um determinado conflito problematizam temas até então colocados como verdades inquestionáveis, e, através de sua atuação política, eles se tornam capazes de revelar novos horizontes para a sociedade.

Essa talvez seja a principal contribuição dos movimentos sociais que lutam por algum tipo de mudança no status quo: relativizar as certezas, colocar em dúvida aquilo que se apresenta como absoluto. A luta pela moradia popular no centro da cidade se encaixa perfeitamente nessa análise. É claro que, no presente contexto, a luta do movimento de moradia não é capaz de alterar profunda e estruturalmente a lógica perversa de produção e organização da cidade. Está longe disso, aliás. Mesmo porque, em tempos de globalização neoliberal, os interesses econô- 
micos que se fazem presentes em uma cidade da importância de São Paulo (o principal elo do Brasil com o circuito financeiro internacional) possuem um poder efetivamente muito maior sobre o controle do território do que os próprios atores políticos locais - a realização da Copa do Mundo em 2014 e dos Jogos Olímpicos em 2016 no Brasil demonstrou isso de forma clara.

Mas o ponto fundamental, na análise desse cenário, é compreender que o movimento de moradia, ao "extrapolar os limites" e reivindicar habitação popular em um lugar onde os pobres não são bem-vindos, mostrou à sociedade que existem outros projetos e concepções sobre a cidade que vão além da perspectiva empresarial ou mercadológica. A luta pela moradia no centro, sobretudo através das ocupações, revela contradições, carências, necessidades e demandas por outra lógica de organização da cidade, que não pode simplesmente ser ignorada pelas autoridades políticas. Com as ocupações em imóveis ociosos no centro da cidade, a lógica periférica de urbanização passou a ser politicamente contestada, e esse é um debate de interesse público. Afinal, o modelo periférico de desenvolvimento urbano trouxe consequências desastrosas para os habitantes dos grandes centros, com destaque para a devastação ambiental (especialmente em razão das ocupações em áreas de mananciais públicos) e a necessidade de grandes deslocamentos pelo território, o que, aliado a uma política que prioriza o transporte individual, tem como desdobramento inevitável o caos absoluto no sistema de trânsito.

Dessa forma, ainda que a pauta do movimento de moradia tenha seu foco voltado para a questão habitacional, sua atuação política contribui para desencadear um debate que é de interesse de toda a sociedade, com exceção daqueles grupos empresariais que continuam extraindo ganhos exorbitantes a partir desse contraditório e conflituoso modelo de desenvolvimento urbano.

Recebido para publicação em 04 de julho de 2016 Aceito em 25 de novembro de 2016

\section{REFERÊNCIAS}

ALONSO, A. Repertório, segundo Charles Tilly: história de um conceito. Sociologia \& Antropologia, v. 2, n. 3, p. 21-41, 2012.

ALONSO, A.; COSTA, V.; MACIEL, D. Identidade e estratégia na formação do movimento ambientalista brasileiro. Novos estudos, n. 79, p. 151-167, nov. 2007.

AQUINO, C. R. F. de. A coletivização como processo de construçấo de um movimento de moradia: uma etnografia do Movimento Sem-Teto do Centro (MSTC). 2008. 201 p. Dissertação (Mestrado em Antropologia) - Faculdade de Filosofia Letras e Ciências Humanas, Universidade de São Paulo, São Paulo, 2008.

BENFORD, R. D.; SNOW, D. Framing processes and social movements. Annual review of Sociology, n. 26, p. 611-639, 2000.

BENOIT, A. H. R. A questão da moradia em Marx e Engels. Crítica Marxista, v. 10, p. 157-160, 2000.

BLIKSTAD, K. O agir coletivo nas interfaces da sociedade civil e do sistema político: o caso da atuação do movimento de moradia de São Paulo sobre a política pública de habitação. 2012. 184 p. Dissertacão (Mestrado em Ciência Política) - Instituto de Filosofia e Ciências Humanas, Universidade Estadual de Campinas, Campinas, 2012.

BONDUKI, N. Crise de habitação e luta pela moradia no pós-guerra. In: KOWARICK, L. (Org.). As lutas sociais e a cidade. São Paulo: Paz e Terra, 1994. p. 113-144.

BONFIM, V. C. Os espaços edificados vazios na área central de São Paulo e a dinâmica urbana. 2004. 132 p. Dissertação (Mestrado em Engenharia) -Escola Polítécnica, Universidade de São Paulo, São Paulo, 2004.

BOULOS, G. Por que ocupamos? Uma introdução à luta dos sem-teto. São Paulo: Scortecci Editora, 2012. 72 p.

CALDEIRA, T. P. do R. Cidade de muros: crime, segregação e cidadania em São Paulo. São Paulo: Editora 34: Edusp, 2008. $399 \mathrm{p}$.

D'ANJOU, L.; MALE, J. V. Between old and new: social movements and cultural change. Mobilization: an international journal, v. 3, n. 2, p. 141-161, 1998.

DAVIS, M. Planeta Favela. São Paulo: Boitempo, 2006. 270 p.

DELLA PORTA, D.; DIANI, M. Social Movements: an introduction. Oxford: Blackwell, 2006. 345 p.

DOIMO, A. M. A vez e a voz do popular: movimentos sociais e participação política no Brasil pós-70. Rio de Janeiro: Relume-Dumará, 1995. 353 p.

FERNANDES, E. Constructing the "right to the city" in Brazil. Social \& legal studies, v.16, n. 2, p. 201-219, 2007.

O estatuto da cidade e a ordem jurídicourbanística. In: CARVALHO, C. S.; ROSSBACH, A. (Org.). O estatuto da cidade comentado. São Paulo: Ministério das Cidades: Aliança das Cidades, 2010. p. 55-70.

FERNANDES, P. O pluralismo paradoxal e os movimentos sociais: democracia participativa e o Estatuto da Cidade. In: JORNADA EM DEFESA DA MORADIA DIGNA, 1. 2008, São Paulo. Anais... São Paulo: Defensoria Público do Estado de São Paulo, 2008. p. 69-83.

GAMSON, W. Talking Politics. Cambridge: Cambridge University Press, 1992. 272 p.

GILLION, D. The political power of protest: minority activism and shifts in public policy. Cambridge: Cambridge University Press, 2013. 191 p.

GIUGNI, M. Was It Worth the Effort? The Outcomes and Consequences of Social Movements. Annual Review of 
Sociology, v. 24, p. 371-393, 1998.

GOHN, M. da G. Movimentos sociais e lutas pela moradia. São Paulo: Edições Loyola, 1991.

HARVEY, D. A justiça social e a cidade. São Paulo: Hucitec, 1980. $291 \mathrm{p}$

KOWARICK, L. A espoliação urbana. Rio de Janeiro: Paz e Terra, 1980. 204 p.

Viver em risco: sobre a vulnerabilidade socioeconômica e civil. São Paulo: Editora 34, 2009. 318 p.

; ANT, C. Cem anos de promiscuidade: o cortiço na cidade de São Paulo. In: KOWARICK, L.; ANT, C. (Org.). As lutas sociais e a cidade. São Paulo: Paz e Terra, 1994. 316 p.

LEFEBVRE, H. $O$ direito à cidade. São Paulo: Centauro, 2008. $144 \mathrm{p}$

MARICATO, E. Metrópole na periferia do capitalismo: ilegalidade, desigualdade e violência. São Paulo: Hucitec, 1996. $141 \mathrm{p}$

As ideias fora do lugar e o lugar fora das ideias. In: ARANTES, O.; VAINER, C.; MARICATO, E. (Org.). A cidade do pensamento único: desmanchando consensos. Petrópolis: Vozes, 2000. 192 p.

MARQUES, E. C. L. A metrópole de São Paulo no século XXI: espaços, heterogeneidades e desigualdades. São Paulo: Editora Unesp: CEM, 2015. 455 p.

McADAM, D.; TARROW, S.; TILLY, C. Para mapear o confronto político. Lua Nova, São Paulo, n. 76, p. 11-48, 2009.

MELO, T de. Direito e ideologia: um estudo a partir da função social da propriedade rural. São Paulo: Outras Expressões: Dobra editorial, 2013. 216 p.

MELUCCI, A. Um objetivo para os movimentos sociais? Lua nova, São Paulo, n. 17, p. 49-66, 1989.

Challenging codes: collective action in the information age. Cambridge: Cambridge University Press, 1996. $455 \mathrm{p}$.

MIAGUSKO, E. Movimentos de moradia e sem-teto em São Paulo: experiências no contexto do desmanche. 2008. 241 p. Tese (Doutorado em Sociologia) - Faculdade de Filosofia Letras e Ciências Humanas, Universidade de São Paulo, São Paulo, 2008.

MOYA, M. E. Os estudos sobre a cidade: quarenta anos - de mudança nos olhares sobre a cidade e o social. In: - KOWARICK, L.; MARQUES, E. (Org.). São Paulo: novos - percursos e atores. São Paulo: Editora 34: Centro de Estudos da metrópole, 2011. 398 p.

NEUHOLD, R. Os movimentos de moradia e sem-teto e as E ocupaçóes de móveis ociosos: a luta por políticas públicas ๗ habitacionais na área central da cidade de São Paulo. 2009.

165 p. Dissertação (Mestrado em Sociologia) - Faculdade de Filosofia Letras e Ciências Humanas, Universidade de เ2 São Paulo, São Paulo, 2009.

2. PASTERNAK, S. Favelas e cortiços no Brasil: 20 anos de pesquisas

$\curvearrowright$ e políticas. Cadernos de Pesquisa do LAP, São Paulo, n. 18, 1997.

Д. PATERNIANI, S. Z. Política, fabulação e a Ocupação Mauá: §ं etnografia de uma experiência. 2013. 256 p. Dissertação $>$ (Mestrado em Antropologia) - Instituto de Filosofia e î Ciências Humanas, Universidade Estadual de Campinas, Campinas, 2013.
PATTO, M. H. S. Estado, ciência e política na Primeira República: a desqualificação dos pobres. Estudos avançados, São Paulo, v. 13, n. 35, p. 167-198, 1999.

RIBEIRO, L. Os movimentos sociais e sua relação com a questão da saúde. Cadernos de Saúde pública, Rio Janeiro, v. 5, n. 3, p. 264-275, jul./set. 1989.

SCHWARZ, R. Um mestre na periferia do capitalismo: Machado de Assis. São Paulo: Duas Cidades: Editora 34, 2000. $250 \mathrm{p}$.

SNOW, D. Framing processes, ideology and discursive field. In: SNOW, D.; SOULE, S.; KRIESI, H. (Org.). The blackwell companion to social movements. Malden: Blackwell, 2004. 754 p.

SNOW, D.; BENFORD, R. Ideology, frame resonance, and participant mobilization. International social movement research, v. 1, p. 197-217, 1988 .

SNOW, D. et al. Frame alignment processes, micromobilization, and movement participation. American sociological review, v. 51, p. 464-81, 1986.

TARROW, S. Power in movement: social movements and contentious politics. Cambridge: Cambridge University Press, 2011. $353 \mathrm{p}$.

TATAGIBA, L.; PATERNIANI, S. Z.; TRINDADE, T. A. Ocupar, reivindicar, participar: sobre o repertório de ação do movimento de moradia de São Paulo. Opinião pública, Campinas, v. 18, n. 2, p. 399-426, nov. 2012.

TAVOLARI, B. Direito à cidade: uma trajetória conceitual. Novos Estudos, n. 104, p. 92-109, mar. 2016.

TILLY, C. From mobilization to revolution. New York: McGraw-Hill, 1978. 349 p.

Why? What happens when people give reasons... and why. Princeton: Princeton University Press, 2006. 202 p.

Contentious performances. Cambridge: Cambridge University Press, 2008. 235 p.

Movimentos sociais como política. Revista brasileira de Ciência política, n. 3, p. 133-160, jan./jul. 2010.

TRINDADE, T. A. Direitos e cidadania: reflexões sobre o direito à cidade. Lua nova, São Paulo, n. 87, p. 139-165, 2012.

Ampliando o debate sobre a participação política e a construção democrática: o movimento de moradia e as ocupações de imóveis ociosos no centro da cidade de São Paulo. 2014. 240 p. Tese (Doutorado em Ciências Sociais) Instituto de Filosofia e Ciências Humanas da Universidade Estadual de Campinas, Campinas, 2014.

A importância dos movimentos sociais e sua relação com o direito: o caso dos movimentos dos sem terra e sem teto no Brasil. In: TRINDADE, E.; MELLIM FILHO, O.; TRINDADE, T. A. (Org.). Curso de Direito: leituras essenciais. Campinas: Editora Alínea, 2015a. p. 147-174.

A participação para além dos espaços institucionais: o movimento de moradia e as ocupacões de imóveis ociosos no centro da cidade de São Paulo (SP). In: ENCONTRO ANUAL DA ASSOCIACÃO NACIONAL DE PÓS-GRADUACÃO EM CIÊNCIAS SOCIAIS (ANPOCS), 39., 2015, Caxambu. Anais... Caxambu: ANPOCS, 2015b.

VILLAÇA, F. Espaço intra-urbano no Brasil. São Paulo: Studio Nobel: FAPESP, 2001.

São Paulo: segregacão urbana e desigualdade. Estudos avançados, São Paulo, v. 25, n. 71, p. 37-58, 2011. 


\section{WHAT DO PROPERTY OCCUPATIONS IN CENTRAL AREAS MEAN?}

\author{
Thiago Aparecido Trindade
}

Taking as an empirical reference the housing movement of the São Paulo downtown, the objective of this article is to analyze the meaning of occupations of unoccupied real estate promoted by actors of this movement in the central area of the city. We try to demonstrate that the role of the social movements as actors who place themselves in the position of challengers of ideas, discourses and hegemonic values in society. By the speech of the activists engaged in this mobilization, it is also discussed how the right of living in downtown became a political agenda gradually built by popular sectors. The method of the study is predominantly qualitative, as it consisted in theoretical review, data collection of documents, journalistic material, and interviews with activists. As a conclusion, we suggest that the main meaning of occupations in the central areas consist in the questioning of the hegemonic model of urbanization in Brazilian society, which historically moved the poorer strata toward the peripheries of the cities.

KEywords: Housing movement. Occupations. Conflict. Right to the city. Urbanization.

\section{QUELLE EST LA SIGNIFICATION DES OCCUPATIONS D'IMMEUBLES DANS DES ZONES CENTRALES?}

\author{
Thiago Aparecido Trindade
}

En prenant comme référence empirique le mouvement pour le logement du centre de Sao Paulo, l'objectif principal de cet article est d'analyser la signification des occupations d'immeubles vides promus par les acteurs de ce mouvement dans le centre de la ville. Nous démontrons ainsi le rôle des mouvements sociaux comme acteurs qui assument une position de défi des idées, des discours et des valeurs hégémoniques dans la société. Par le biais des discours des activistes eux-mêmes engagés dans cette mobilisation, il y a lieu de savoir aussi comment le droit d'habiter au centre de la ville est devenu un sujet politique construit progressivement par les secteurs populaires. La méthodologie adoptée, essentiellement qualitative, a consisté en une révision de la théorie, une collecte de données issue de documents et de matériel journalistique ainsi que d'interviews avec des militants. Pour conclure, nous estimons que le sens principal de l'occupation des aires centrales consiste en une remise en question du modèle hégémonique de l'urbanisation dans la société brésilienne qui, tout au long de l'histoire a éloigné les couches plus pauvres vers les ceintures périphériques des villes.

Mots-CLÉs: Mouvement pour le logement. Occupations. Conflit. Droit à la ville. Urbanisation.

Thiago Aparecido Trindade - Doutor em Ciências Sociais pelo IFCH/Unicamp. Professor do Instituto de Ciência Política da Universidade de Brasília (UnB). Membro do Grupo de Pesquisa sobre Democracia e Desigualdades (Demodê), onde coordena a linha de pesquisa Democracia e Ativismo Político e desenvolve pesquisas sobre movimentos sociais. Foi professor de ensino superior na Faculdade de Campinas e na Faculdade de Jaguariúna entre 2012 e 2015. Publicações recentes: Protesto e democracia: ocupações urbanas e luta pelo direito à cidade”. 2017. Direitos e cidadania: reflexões sobre o direito à cidade. Lua Nova, n. 87, p. 139-165, 2012. Curso de direito: leituras essenciais”, 2015, em coautoria com Edi Aparecido Trindade e Oscar Mellim Filho. 
